\title{
Aging and Coronavirus: Exploring Complementary Therapies to Avoid Inflammatory Overload
}

\author{
Leônidas Oliveira Neto ${ }^{1 *}$, Vagner Deuel de Oliveira Tavares ${ }^{2}$, Nicole Leite Galvão-Coelho ${ }^{2}$, \\ Felipe Barreto Schuch ${ }^{3}$ and Kenio Costa Lima ${ }^{4}$
}

${ }^{1}$ Department in Arts, Federal University of Rio Grande do Norte, Natal, Brazil, ${ }^{2}$ Laboratory of Hormonal Measurements, Department of Physiology and Behavior, Brazil and National Institute of Science and Technology in Translational Medicine, Federal University of Rio Grande do Norte, Natal, Brazil, ${ }^{3}$ Department of Sports Methods and Techniques, Federal University of Santa Maria, Santa Maria, Brazil, ${ }^{4}$ Department of Odontology, Federal University of Rio Grande do Norte, Natal, Brazil

Keywords: lifestyle, nutraceuticals, coronavirus, health, inflammation

\section{OVERVIEW}

Acute respiratory distress syndrome (ARDS) is the main cause of death in COVID-19 patients $(1,2)$. In recent years the relationship between this respiratory syndrome and inflammatory system dysregulation has been discussed (3). Patients with ARDS could present distinct endophenotypes with respect to immune alterations: hyper- or hypo-inflammatory profiles $(4,5)$.

The identification of inflammatory endophenotypes of ARDS is important, as patients respond

OPEN ACCESS

Edited by:

Emanuele Marzetti,

Catholic University of the Sacred

Heart, Italy

Reviewed by:

Maturin Tabue-Teguo,

Université des Antilles et de la

Guyane, France

*Correspondence:

Leônidas Oliveira Neto

leonidasoliveiraneto@gmail.com

Specialty section:

This article was submitted to Geriatric Medicine

a section of the journal

Frontiers in Medicine

Received: 07 May 2020

Accepted: 15 June 2020

Published: 26 June 2020

Citation:

Neto LO, Tavares VDdO,

Galvão-Coelho NL, Schuch FB and

Lima KC (2020) Aging and

Coronavirus: Exploring

Complementary Therapies to Avoid

Inflammatory Overload.

Front. Med. 7:354.

doi: 10.3389/fmed.2020.00354 differently to clinical and hospital management (3). In patients with a hyper-inflammatory profile, a pro-inflammatory storm is observed in the human body, with elevated rates of biomarkers such as C Reactive Protein (CRP) $(2,6)$ and cytokines such as interleukins (IL)-6 and tumoral necrosis factor (TNF)- $\alpha$ that are able to develop a systemic inflammatory response. The release of IL- 6 and TNF- $\alpha$ into the systemic circulation directly contributes to the increase in systemic inflammation levels and arteriosclerosis processes (7).

People with chronic clinical comorbidities (1) such as hypertension, diabetes (8), and kidney disease (9) have a higher risk of becoming critically ill and dying from COVID-19. For this reason, the older age population has a higher risk of mortality by COVID-19, since they have many of these diseases $(10,11)$. It is interesting to highlight that both aging and chronic diseases are linked to an increase in levels of systemic inflammation, which could explain a potential common pathway between these factors and COVID-19. Therefore, the acute and strong immune system dysregulation induced by the virus may be linked to ARDS and its complications, such as multiple organ failure, and finally lead to patient death (12), mainly in those with previous inflammatory allostatic overload $(13,14)$.

In fact, people with COVID-19 present high levels of systemic inflammatory biomarkers (15), and the detection of these forms part of the preliminary guidelines for the diagnosis and treatment of SARS-CoV-2 (12). Accordingly, multiple experimental treatments with immune-suppressing or stimulating drugs have been tested, aiming to reduce the pro-inflammatory cascade and, thus, mortality (16-18).

While the search for effective treatments and vaccines is the top priority, non-pharmacological complementary therapies targeting reductions in baseline inflammatory load, mainly in the oldest population, should receive some attention. During aging, a natural and progressive deterioration in cells and impairment in organ functions occur due to metabolic, immunological, neuroendocrine, or oxidative stress (19). At a molecular level, imbalance between the oxidant/antioxidant pathways (19) could be explained by malfunction in inflammatory/antiinflammatory homeostatic mechanisms, which result in a chronic low-grade pro-inflammatory state known as inflammaging (20). 
The inflammatory system is responsible for defending systemic functioning and repairing damages from infections and harmful environmental agents. Aging is a process that all living organisms ages and corresponds to a reduction of defenses to the aggressor agents of living beings, and this we call immunosenescence. This process is gradual and differs between genders (21). At $\sim 40$ years of age, the first major reduction in immune functions occurs and occurs in a similar way between men and women. Studies with COVID-19 reveal that it is exactly in this age group that lethality doubles, from 0.2 to $0.4 \%$. Around the early post- $60 \mathrm{~s}$, we have a new functional immune decline for men, which only occurs in the late 60 s for women, which may partly explain the higher mortality of men worldwide (22). Several studies report that, with aging, both the innate and adaptive immune response suffer changes both in their cellular composition and in their function $(23,24)$. In the case of COVID-19, the innate immune response in the elderly would be activated, and there would be no satisfactory passage of the innate immune response to adaptive, maintaining a chronic activation of the former and preventing the elimination of SARS-CoV2 $(23,25)$.

In addition to maintaining the chronic immune response, which generates a chronic inflammatory state, there is an important decline in the performance of the adaptive system. Yet, there is a reduction in the recognition of new antigens by adaptive immunity due to the reduction of naive cells and, moreover, a depletion of aging immune cells, which are already very stimulated and do not retain their functions. There are reports that immune cells of adaptive response also undergo changes in their functions and start to act as cells of the innate response (26). During the COVID-19 pandemic, two of the proinflammatory proteins were elevated in severe patients (27), yet the inflammatory state may be associated with multiple diseases (25).

In this sense, the consequences are systemic and affect the elderly especially, causing changes in body composition and an imbalance between availability and energy demand that can affect the quality of life and functionality of the elderly (28). In addition, the inflammation overload makes the elderly more susceptible to several other diseases, such as cardiovascular disease, diabetes, osteoporosis, and ostearthrosis (29).

In this context, lifestyle and nutraceuticals arise as important prophylactic interventions to reduce the burden of baseline inflammation in older adults and consequently improve quality of life, mobility, cognition, mood, and metabolic and immune balances, especially during the pandemic. It is possible that COVID-19 will be a long pandemic, with multiple infection waves (30); therefore, these strategies are especially important since they can be adopted in the long term and under physical social isolation.

The aim of this study is to discuss how diet and nutraceuticals and lifestyle as complementary therapies could help older adults during the COVID-19 pandemic, reducing inflammaging.

\section{DIET AND NUTRACEUTICALS}

Comfort foods are very palatable foods that are rich in saturated fats and carbohydrates, especially sugar, which can decrease stress and anxiety through activation of the dopaminergic pathways of the reward system $(31,32)$. In times of lockdown, a rise in the intake of comfort foods is likely, and this behavior tends to strengthen each time the reward system is activated (33). Since comfort foods have a high caloric rate, they can lead to weight gain when the energy expenditure is lower than the caloric intake, resulting in obesity, which is recognized as an inflammatory disease (34).

In order to avoid weight gain, which adds load to inflammaging through an increase in the synthesis of harmful adipocytokines by white adipose tissue (35), a diet should be prescribed by a specialist. For instance, some diets, such as the Mediterranean diet, the low glycemic index diet, moderate carbohydrate intake, and vegetarian diets, should be adapted to the personal demands and preferences of older adults and prescribed in times of lockdown (36). However, diets with severe restriction should be avoided, as they could lead to impulsive food behaviors (31).

Besides adjustment in the diet, some specific nutrient supplementations can assist in health improvement, such as magnesium, zinc, S-adenosyl methionine, omega-3, and vitamin $\mathrm{D}$, which are important for good maintenance of cognitive and physiological mechanisms $(37,38)$. Magnesium is fundamental for nervous system function and insulin sensitivity, helping in the prevention or management of Diabetes Mellitus type II, characterized as a chronic and mild inflammatory disease (34, 39). Zinc also contributes to improving insulin sensitivity (40) and body metabolism (39). Vitamin D, or more specifically, 25hydroxyvitamin D [25 (OH) D], is an anti-inflammatory nutrient (41), and reduces the activation of the renin-angiotensin system, preventing hypertension (42), besides its importance to bone and muscle, an inverse relationship is also observed between its levels and mortality risk in old adults (43). Omega-3 has an important role in cognition and as an anti-inflammatory agent; thus, it seems effective against age-related mood disorder $(44,45)$.

Recently, 25-hydroxyvitamin D [25(OH)D] has been suggested as a nutraceutical alternative to reduce the risk of COVID-19 infection due to improvement in the immune system, whereas vitamin D3 is pointed out as an adjunctive treatment in higher doses $(1,46)$. In addition, vitamin $C$ could be an alternative to treat respiratory tract infections. Also, one study indicated that administration of $\sim 15 \mathrm{~g}$ /day of vitamin $\mathrm{C}$ for 4 days may decrease mortality in patients with ARDS (47). However, the vitamin $\mathrm{C}$ supplementation did not significantly improve organ dysfunction scores or alter biomarkers of inflammation and vascular injury. Thus, controlled trials and large-population studies should be conducted to prove these hypotheses.

Moreover, it is important to highlight that the benefits of both diet and nutraceutical interventions are enhanced and the risks reduced when planned for a specific patient, through precisionbased approaches that consider nutritional macro/micronutrient deficiencies, levels of inflammatory cytokines, and genomic and 
microbiome analysis, among other factors (48). This individual analysis is mainly relevant to elderly adults who usually show imbalances in many micro- and macronutrient levels as a result of aging or pharmacological treatments. Although some of these approaches are low-cost, unhappily, they are not always applied. Therefore, their use should be stimulated to has to help reduce the number of deaths around the world, mainly during the pandemic (49).

\section{SEDENTARY BEHAVIOR AND LIFESTYLE THERAPY}

Sedentary behaviors such as longer screen time and lower physical energy expenditure can aggravate physical and mental conditions (50), especially in this period of social isolation. Therefore, reducing the time spent in sedentary behavior at home is of great importance for maintaining health during lockdown (51). Furthermore, increasing the time spent engaging in exercise is essential.

Lifestyle therapy consists of adopting a health routine that includes a balanced diet, physical exercise, relaxation and meditation techniques, and good sleep $(38,48)$.

A robust body of evidence has demonstrated the benefits of these modifications of lifestyle for mental health, mainly for mood symptoms (52-55), indicating that lifestyle therapy is an effective strategy for preventing and treating some mental disorders (56-59), including in old adults (45).

It is natural that with aging, the frequency and intensity of physical activities will decrease (51). However, there are further reasons for encouraging an increase in activity levels, such as for improving cardiorespiratory fitness (60), which in turn reduces mortality risk (61), and poor health (62). Furthermore, reducing sedentary behavior and engaging in exercise may increasing the production of systemic anti-inflammatory cytokines and help to combat inflammation $(63,64)$ by increasing innate immune function (65) and decreasing the chronic inflammation related to various diseases (66).

Considering the high rate of risk factors being present in older adults as a risk group (67), it is necessary to build tools directed at this group that aim to reduce sedentary behaviors and to keep them active during the COVID-19 pandemic. As well as setting prescribed exercises and encouraging increased levels of daily physical activity, all movements should be stimulated, even simple routine activities such as those related to cleaning the house (68).

With respect to exercises, to reduce sedentary behavior, we recommend the practice of modest exercises that are popularly known as jumping jacks, going up and down stairs, pushups, sit and get up, and balance exercises. These exercises are options that can fit well into the lockdown situation and can be done with home objects such as chairs and benches. However, all exercise should be supervised and prescribed by a trained professional, considering the individual, social, and economic aspects of the subject. However, it is necessary that this orientation occurs using distance-oriented tools, such as internet-based strategies like apps or video calls or mobile telephone messages. Group classes can also improve motivation and social support, which in turn reduces psychological stress levels, helping in homeostatic balance (69).

However, as some elderly adults have impaired motor skills, other alternatives have been used to reduce symptoms of mental disorders and reduction inflammation. For this, approaches with an integrative mind-body focus have been gaining ground in order to prevent or treat diseases such as chronic stress, anxiety, and depression (70), which are known to induce a mildly proinflammatory profile (71). These approaches use meditative practices as tools aimed at refining attention and promoting better emotional regulation and self-awareness (72). One of the main components of mindfulness-based activities is the regulation of attention (73). Thus, attentional focus during the exercises proposed in mindfulness programs is directed to the observation of the experience of thoughts, body sensations, and emotions $(74,75)$. In addition, the practice of relaxation and meditation also has an effect on reducing inflammation (76).

Successful mind-body interventions in older adults have shown improvements in different aspects, such as pain control, sleep quality, attention, global cognition, and working memory (77). Additionally, positive results were recently presented for the reduction of depressive symptoms through internet mindfulness therapy in this population (78). Therefore, applying relaxation and meditation therapies is urgent, as these can improve mental and physical health in older people who are in isolation, following the guidelines of the WHO.

\section{CONCLUSION}

Social physical isolation due to COVID-19 can bring serious risks to health if older adults continue with, or assume, a nonhealthy lifestyle, which includes a lack of physical activity and a diet low in nutrients and rich in comfort foods. Therefore, strategies should be encouraged to promote and raise awareness among the older population about the application of lifestyle and nutraceutical tools. These interventions have great potential for insertion in public policies in different contexts due to their low cost, effectiveness, and simplicity. We are aware that it can be difficult to apply all of these suggestions, mainly in elderly adults, but every step is important and better than none. Therefore, a healthy lifestyle should be encouraged as an intervention to prevent frailty among older people, and a multi-professional care system should act in this time of COVID-19 to reduce risks and avoid damage related to inflammation overload in older adults.

\section{AUTHOR CONTRIBUTIONS}

LN: conceptualization, project administration, and writingoriginal draft preparation. VT, NG-C, and FS: reviewing and editing. KL: conceptualization, project administration, and writing-original draft preparation. All authors contributed to the article and approved the submitted version. 


\section{FUNDING}

The authors declare that this study was conducted in the absence of any commercial or financial relationships that could be construed as a potential conflict of interest. NG-C

\section{REFERENCES}

1. Kakodkar P, Kaka N, Baig MN. A comprehensive literature review on the clinical presentation, and management of the pandemic coronavirus disease 2019 (COVID-19). Cureus. (2020) 12:e7560. doi: 10.7759/cureus.7560

2. Huang C, Wang Y, Li X, Ren L, Zhao J, Hu Y, et al. Clinical features of patients infected with 2019 novel coronavirus in Wuhan, China. Lancet. (2020) 395:497-506. doi: 10.1016/S0140-6736(20)30183-5

3. Nanchal RS, Truwit JD. Recent advances in understanding and treating acute respiratory distress syndrome [version 1; referees: 2 approved]. F1000Research. (2018) 7:1-9. doi: 10.12688/f1000research.15493.1

4. Dimitrova N, Zamudio JR, Jong RM, Soukup D, Resnick R, Sarma K, et al. Latent class analysis of ARDS subphenotypes: analysis of data from two randomized controlled trials carolyn. Lancet Respir Med. (2017) 32:736-740. doi: 10.1016/S2213-2600(14)70097-9

5. Famous KR, Delucchi K, Ware LB, Kangelaris KN, Liu KD, Thompson BT, et al. Acute respiratory distress syndrome subphenotypes respond differently to randomized fluid management strategy. Am J Respir Crit Care Med. (2017) 195:331-8. doi: 10.1164/rccm.201603-0645OC

6. Williams AE, Chambers RC. The mercurial nature of neutrophils: still an enigma in ARDS? Am J Physiol Lung Cell Mol Physiol. (2014) 306:L21730. doi: 10.1152/ajplung.00311.2013

7. Vega-Robledo GB, Rico-Rosillo MG. Adipose tissue: immune function and alterations caused by obesity. Rev Alerg Mex. (2019) 66:34053. doi: 10.29262/ram.v66i3.589

8. Bornstein SR, Dalan R, Hopkins D, Mingrone G, Boehm BO. Endocrine and metabolic link to coronavirus infection. Nat Rev Endocrinol. (2020) 16:1-2. doi: 10.1038/s41574-020-0353-9

9. Cheng Y, Luo R, Wang K, Zhang M, Wang Z, Dong L, et al. Kidney disease is associated with in-hospital death of patients with COVID-19. Kidney Int. (2020) 97:1-10. doi: 10.1101/2020.02.18.20023242

10. Porcheddu R, Serra C, Kelvin D, Kelvin N, Rubino S. Similarity in case fatality rates (CFR) of COVID-19/SARS-COV-2 in Italy and China. J Infect Dev Ctries. (2020) 14:125-8. doi: 10.3855/jidc.12600

11. Ruan Q, Yang K, Wang W, Jiang L, Song J. Clinical predictors of mortality due to COVID-19 based on an analysis of data of 150 patients from Wuhan, China. Intensive Care Med. (2020) 46:846-8. doi: 10.1007/s00134-020-06028-z

12. Li T. Diagnosis and clinical management of severe acute respiratory syndrome Coronavirus 2 (SARS-CoV-2) infection: an operational recommendation of Peking Union Medical College Hospital (V2.0): Working Group of 2019 Novel Coronavirus, Peking Union Medical Colle. Emerg Microbes Infect. (2020) 9:582-5. doi: 10.1080/22221751.2020.1735265

13. McEwen BS. Interacting mediators of allostasis and allostatic load: towards an understanding of resilience in aging. Metabolism. (2003) 52:106. doi: 10.1016/S0026-0495(03)00295-6

14. Logan JG, Barksdale DJ. Allostasis and allostatic load: expanding the discourse on stress and cardiovascular disease. J Clin Nurs. (2008) 17:2018. doi: 10.1111/j.1365-2702.2008.02347.x

15. Conti P, Ronconi G, Caraffa A, Gallenga C, Ross R, Frydas I, et al. Induction of pro-inflammatory cytokines (IL-1 and IL-6) and lung inflammation by Coronavirus-19 (COVI-19 or SARS-CoV-2): anti-inflammatory strategies. $J$ Biol Regul Homeost Agents. (2020) 2:34. doi: 10.23812/CONTI-E

16. Russell B, Moss C, George G, Santaolalla A, Cope A, Papa S, et al. Associations between immune-suppressive and stimulating drugs and novel COVID19-a systematic review of current evidence. Ecancermedicalscience. (2020) 14:1022. doi: 10.3332/ecancer.2020.1022

17. Gharebaghi R, Heidary F, Moradi M, Parvizi M. Metronidazole a potential novel addition to the COVID-19 treatment regimen. SSRN Electron J. (2020) 8:5-7. doi: $10.2139 /$ ssrn. 3559020 was supported by the CAPES Foundation of the Brazilian Ministry of Education (Research Fellowship 88887.466701/201900 ) and the National Science and Technology Institute for Translational Medicine (INCT-TM Fapesp 2014/50891-1; CNPq 465458/2014-9).

18. Zhang W, Zhao Y, Zhang F, Wang Q, Li T, Liu Z, et al. The use of antiinflammatory drugs in the treatment of people with severe coronavirus disease 2019 (COVID-19): the experience of clinical immunologists from China. Clin Immunol. (2020) 214:108393. doi: 10.1016/j.clim.2020.108393

19. Oliveira BF, Nogueira-Machado JA, Chaves MM. The role of oxidative stress in the aging process. ScientificWorldJournal. (2010) 10:1121-8. doi: 10.1100/tsw.2010.94

20. Candore G, Caruso C, Colonna-Romano G. Inflammation, genetic background and longevity. Biogerontology. (2010) 11:56573. doi: 10.1007/s10522-010-9286-3

21. Bartz D, Chitnis T, Kaiser UB, Rich-Edwards JW, Rexrode KM, Pennell $\mathrm{PB}$, et al. Clinical advances in sex- and gender-informed medicine to improve the health of all: a review. JAMA Intern Med. (2020) 180:57483. doi: 10.1001/jamainternmed.2019.7194

22. Márquez EJ, Trowbridge J, Kuchel GA, Banchereau J, Ucar D. The lethal sex gap: COVID-19. Immun Ageing. (2020) 17:13. doi: 10.1186/s12979-020-00183-Z

23. Fulop T, Larbi A, Dupuis G, Page A Le, Frost EH, Cohen AA, et al. Immunosenescence and inflamm-aging as two sides of the same coin: friends or foes? Front Immunol. (2018) 8:1960. doi: 10.3389/fimmu.2017.01960

24. Nikolich-Žugich J. The twilight of immunity: emerging concepts in aging of the immune system review-article. Nat Immunol. (2018) 19:109. doi: 10.1038/s41590-017-0006-x

25. Furman D, Campisi J, Verdin E, Carrera-Bastos P, Targ S, Franceschi C, et al. Chronic inflammation in the etiology of disease across the life span. Nat Med. (2019) 25:1822-32. doi: 10.1038/s41591-019-0675-0

26. Pereira BI, De Maeyer RPH, Covre LP, Nehar-Belaid D, Lanna A, Ward S, et al. Sestrins induce natural killer function in senescent-like CD8+ T cells. Nat Immunol. (2020) 21:684-94. doi: 10.1038/s41590-020-0643-3

27. Qin C, Zhou L, Hu Z, Zhang S, Yang S, Tao Y, et al. Dysregulation of immune response in patients with COVID-19 in Wuhan, China. Clin Infect Dis. (2020) 2019:4-10. doi: 10.2139/ssrn.3541136

28. Rea IM, Gibson DS, McGilligan V, McNerlan SE, Denis Alexander H, Ross OA. Age and age-related diseases: role of inflammation triggers and cytokines. Front Immunol. (2018) 9:586. doi: 10.3389/fimmu.2018.00586

29. Bektas A, Schurman SH, Sen R, Ferrucci L. Aging, Inflammation and the Environment. Exp Gerontol. (2018) 105:10-8. doi: 10.1016/j.exger.2017.12.015

30. Kissler SM, Tedijanto C, Goldstein E, Grad YH, Lipsitch M. Projecting the transmission dynamics of SARS-CoV-2 through the postpandemic period. medRxiv. (2020) 368:860-8. doi: 10.1101/2020.03.04.20031112

31. Adam TC, Epel ES. Stress, eating and the reward system. Physiol Behav. (2007) 4:449-58. doi: 10.1016/j.physbeh.2007.04.011

32. Dallman MF, La Fleur SE, Pecoraro NC, Gomez F, Houshyar H, Akana SF. Minireview: glucocorticoids - food intake, abdominal obesity, and wealthy nations in 2004. Endocrinology. (2004) 145:2633-8. doi: 10.1210/en.2004-0037

33. Warne JP. Shaping the stress response: interplay of palatable food choices, glucocorticoids, insulin and abdominal obesity. Mol Cell Endocrinol. (2009) 300:137-46. doi: 10.1016/j.mce.2008.09.036

34. Ellulu MS, Patimah I, Khaza'ai H, Rahmat A, Abed Y. Obesity \& inflammation: the linking mechanism \& the complications. Arch Med Sci. (2017) 13:85163. doi: 10.5114 /aoms.2016.58928

35. Scheja L, Heeren J. The endocrine function of adipose tissues in health and cardiometabolic disease. Nat Rev Endocrinol. (2019) 15:50724. doi: 10.1038/s41574-019-0230-6

36. Van Gaal LF, Maggioni AP. Overweight, obesity, and outcomes: fat mass and beyond. Lancet. (2014) 383:935-6. doi: 10.1016/S0140-6736(13)62076-0

37. Sarris J, Logan AC, Akbaraly TN, Amminger GP, Balanzá-Martínez V, Freeman MP, et al. Nutritional medicine as mainstream in psychiatry. Lancet Psychiatry. (2015) 2:271-4. doi: 10.1016/S2215-0366(14)00051-0 
38. Sarris J, Murphy J, Mischoulon D, Papakostas GI, Fava M, Berk $M$, et al. Adjunctive nutraceuticals for depression: a systematic review and meta-analyses. Am J Psychiatry. (2016) 173:575-87. doi: 10.1176/appi.ajp.2016.15091228

39. Gröber U, Schmidt J, Kisters K. Magnesium in prevention and therapy. Nutrients. (2015) 7:8199-226. doi: 10.3390/nu7095388

40. Chukwuma CI, Mashele SS, Eze KC, Matowane GR, Islam SM, Bonnet SL, et al. A comprehensive review on zinc(II) complexes as anti-diabetic agents: the advances, scientific gaps and prospects. Pharmacol Res. (2020) 155:652-4. doi: $10.1016 /$ j.phrs.2020.104744

41. Maruotti N, Cantatore FP. Vitamin D and the immune system.J Rheumatol. (2010) 37:491-5. doi: 10.3899/jrheum.090797

42. Santoro D, Caccamo D, Lucisano S, Buemi M, Sebekova K, Teta D, et al. Interplay of Vitamin D, erythropoiesis, and the renin-angiotensin system. Biomed Res Int. (2015) 2015:145828. doi: 10.1155/2015/145828

43. Hill TR, Granic A, Aspray TJ. Vitamin D and ageing. Subcell Biochem. (2018) 90:191-220. doi: 10.1007/978-981-13-2835-0_8

44. Giacobbe J, Benoiton B, Zunszain P, Pariante CM, Borsini A. The antiinflammatory role of Omega-3 polyunsaturated fatty acids metabolites in preclinical models of psychiatric, neurodegenerative, and neurological disorders. Front Psychiatry. (2020) 11:122. doi: 10.3389/fpsyt.2020.00122

45. Farioli-Vecchioli S, Sacchetti S, di Robilant NV, Cutuli D. The role of physical exercise and Omega-3 fatty acids in depressive illness in the elderly. Curr Neuropharmacol. (2018) 16:308-26. doi: 10.2174/1570159X15666170912113852

46. Grant WB, Lahore H, McDonnell SL, Baggerly CA, French CB, Aliano JL, et al. Evidence that Vitamin D supplementation could reduce risk of influenza and COVID-19 infections and deaths. Nutrients. (2020) 12:988. doi: 10.3390/nu12040988

47. Fowler AA, Truwit JD, Hite RD, Morris PE, Dewilde C, Priday A, et al. Effect of Vitamin C infusion on organ failure and biomarkers of inflammation and vascular injury in patients with sepsis and severe acute respiratory failure: the CITRIS-ALI randomized clinical trial. JAMA J Am Med Assoc. (2019) 322:1261-70. doi: 10.1001/jama.2019.11825

48. Sarris J, Byrne GJ, Stough C, Bousman C, Mischoulon D, Murphy J, et al. Nutraceuticals for major depressive disorder- more is not merrier: an 8-week double-blind, randomised, controlled trial. J Affect Disord. (2019) 245:100715. doi: 10.1016/j.jad.2018.11.092

49. Rattan SIS, Sejersen H, Fernandes RA, Luo W. Stress-mediated hormetic modulation of aging, wound healing, and angiogenesis in human cells. Ann N Y Acad Sci. (2007) 1119:112-21. doi: 10.1196/annals.1404.005

50. Werneck AO, Oyeyemi AL, Collings PJ, Cyrino ES, Ronque ERV, Szwarcwald $\mathrm{CL}$, et al. Physical activity can attenuate, but not eliminate, the negative relationships of high TV viewing with some chronic diseases: findings from a cohort of 60202 Brazilian adults. J Public Health. (2019). doi: 10.1093/pubmed/fdz148. [Epub ahead of print].

51. Schuch FB, Bulzing RA, Meyer J, Vancampfort D, Firth J, Stubbs B, et al. Associations of moderate to vigorous physical activity and sedentary behavior with depressive and anxiety symptoms in self-isolating people during the COVID-19 pandemic: a cross-sectional survey in Brazil. Sci Electron Libr Online. (2020) 1-27. doi: 10.1590/SciELOPreprints.526

52. Stubbs B, Vancampfort D, Hallgren M, Firth J, Veronese N, Solmi M, et al. EPA guidance on physical activity as a treatment for severe mental illness: a meta-review of the evidence and Position Statement from the European Psychiatric Association (EPA), supported by the International Organization of Physical Therapists in Mental. Eur Psychiatry. (2018) 54:12444. doi: 10.1016/j.eurpsy.2018.07.004

53. Firth J, Siddiqi N, Koyanagi A, Siskind D, Rosenbaum S, Galletly C, et al. The lancet psychiatry commission: a blueprint for protecting physical health in people with mental illness. Lancet Psychiatry. (2019) 6:675712. doi: 10.1016/S2215-0366(19)30132-4

54. Vancampfort D, Rosenbaum S, Schuch F, Ward PB, Richards J, Mugisha J, et al. Cardiorespiratory fitness in severe mental illness: a systematic review and meta-analysis. Sport Med. (2017) 47:343-52. doi: 10.1007/s40279-016-0574-1

55. Firth J, Stubbs B, Rosenbaum S, Vancampfort D, Malchow B, Schuch F, et al. Aerobic exercise improves cognitive functioning in people with schizophrenia: a systematic review and meta-analysis. Schizophr Bull. (2017) 43:546-56. doi: 10.1093/schbul/sbw115
56. Schuch FB, Vancampfort D, Richards J, Rosenbaum S, Ward $\mathrm{PB}$, Stubbs B. Exercise as a treatment for depression: a metaanalysis adjusting for publication bias. J Psychiatr Res. (2016) 77:42-51. doi: 10.1016/j.jpsychires.2016.02.023

57. Ashdown-Franks G, Firth J, Carney R, Carvalho AF, Hallgren M, Koyanagi $\mathrm{A}$, et al. Exercise as medicine for mental and substance use disorders: a metareview of the benefits for neuropsychiatric and cognitive outcomes. Sport Med. (2019) 50:151-70. doi: 10.1007/s40279-019-01187-6

58. Schuch FB, Stubbs B, Meyer J, Heissel A, Zech P, Vancampfort D, et al. Physical activity protects from incident anxiety: a meta-analysis of prospective cohort studies. Depress Anxiety. (2019) 36:846-58. doi: 10.1002/da. 22915

59. Schuch FB, Vancampfort D, Firth J, Rosenbaum S, Ward PB, Silva ES, et al. Physical activity and incident depression: a metaanalysis of prospective cohort studies. Am J Psychiatry. (2018) 175:631-48. doi: 10.1176/appi.ajp.2018.17111194

60. Garber CE, Blissmer B, Deschenes MR, Franklin BA, Lamonte MJ, Lee IM, et al. Quantity and quality of exercise for developing and maintaining cardiorespiratory, musculoskeletal, and neuromotor fitness in apparently healthy adults: guidance for prescribing exercise. Med Sci Sports Exerc. (2011) 43:1334-59. doi: 10.1249/MSS.0b013e318213fefb

61. Lee IM, Shiroma EJ, Lobelo F, Puska P, Blair SN, Katzmarzyk PT. Impact of physical inactivity on the world's major non-communicable diseases. Lancet. (2012) 380:219-29. doi: 10.1016/S0140-6736(12) 61031-9

62. Blair S, Cheng Y, Holder J. Is physical activity or physical fitness more important in defining health benefits? Med Sci Sport Exerc. (2001) 33:S37999. doi: 10.1097/00005768-200106001-00007

63. Ostrowski K, Rohde T, Asp S, Schjerling P, Pedersen BK. Pro- and antiinflammatory cytokine balance in strenuous exercise in humans. J Physiol. (1999) 515:287-91. doi: 10.1111/j.1469-7793.1999.287ad.x

64. Petersen AMW, Pedersen BK. The anti-inflammatory effect of exercise. J Appl Physiol. (2005) 98:1154-62. doi: 10.1152/japplphysiol.00164.2004

65. Woods JA, Lowder TW, Keylock KT. Can exercise training improve immune function in the aged? Ann N Y Acad Sci. (2002) 959:11727. doi: $10.1111 / j .1749-6632.2002 . t b 02088 . x$

66. Kohut ML, Senchina DS. Reversing age-associated immunosenescence via exercise. Exerc Immunol Rev. (2004) 10:6-41.

67. Armitage R, Nellums LB. COVID-19 and the consequences of isolating the elderly. Lancet Public Health. (2020) 2667:30061. doi: 10.1016/S2468-2667(20)30061-X

68. de Oliveira Neto L, Elsangedy HM, de Oliveira Tavares VD, Teixeira CV, Behm DG, Da Silva-Grigoletto ME. \#TrainingInHome - training at home during the COVID-19 (SARS-COV2) pandemic: physical exercise and behavior-based approach. Brazilian J Exerc Physiol. (2020) 19:919. doi: $10.33233 /$ rbfe.v19i2.4006

69. Galvão-Coelho NL, Silva HPA, de Sousa MBC. Resposta ao estresse: II. Resiliência e vulnerabilidade. Estud Psicol. (2015) 20:72-81. doi: 10.5935/1678-4669.20150009

70. Brinsley J, Schuch F, Lederman O, Girard D, Smout M, Immink MA, et al. Effects of yoga on depressive symptoms in people with mental disorders: a systematic review and meta-analysis. Br J Sport Med. (2020) 1-10. doi: 10.1136/bjsports-2019-101242

71. Raison CL, Miller AH. Is depression an inflammatory disorder? Curr Psychiatry Rep. (2011) 13:467-75. doi: 10.1007/s11920-011-0232-0

72. Kabat-Zinn J, Lipworth L, Burney R. The clinical use of mindfulness meditation for the self-regulation of chronic pain. J Behav Med. (1985) 8:163-90. doi: 10.1007/BF00845519

73. Bishop SR, Lau M, Shapiro S, Carlson L, Anderson ND, Carmody J, et al. Mindfulness: a proposed operational definition. Clin Psychol Sci Pract. (2004) 11:230-41. doi: 10.1093/clipsy.bph077

74. Kabat-Zinn J. Full Catastrophe Living: Using the Wisdom of Your Body and Mind to Face Stress, Pain, and Illness. The Random House Publishing Group (1990).

75. Hölzel BK, Lazar SW, Gard T, Schuman-Olivier Z, Vago DR, Ott U. How does mindfulness meditation work? Proposing mechanisms of action from a conceptual and neural perspective. Perspect Psychol Sci. (2011) 6:53759. doi: $10.1177 / 1745691611419671$ 
76. Black DS, Slavich GM. Mindfulness meditation and the immune system: a systematic review of randomized controlled trials. Ann N Y Acad Sci. (2017) 176:139-48. doi: 10.1111/nyas.12998

77. Zhang JX, Liu XH, Xie XH, Zhao D, Shan MS, Zhang XL, et al. Mindfulness-based stress reduction for chronic insomnia in adults older than 75 years: a randomized, controlled, single-blind clinical trial. Explor J Sci Heal. (2015) 11:180-5. doi: 10.1016/j.explore.2015. 02.005

78. Wahbeh $\mathrm{H}$. Internet mindfulness meditation intervention (IMMI) improves depression symptoms in older adults. Medicines. (2018) 5:119. doi: 10.3390/medicines5040119
Conflict of Interest: The authors declare that the research was conducted in the absence of any commercial or financial relationships that could be construed as a potential conflict of interest.

Copyright (C) 2020 Neto, Tavares, Galvão-Coelho, Schuch and Lima. This is an openaccess article distributed under the terms of the Creative Commons Attribution License (CC BY). The use, distribution or reproduction in other forums is permitted, provided the original author(s) and the copyright owner(s) are credited and that the original publication in this journal is cited, in accordance with accepted academic practice. No use, distribution or reproduction is permitted which does not comply with these terms. 